\title{
Advanced Controllers Implementation for Speed Control Analysis of Two Mass Drive System
}

\author{
D.Devasena $^{1}$, B.Sharmila ${ }^{2}$, Coimbatore S.Kaushik ${ }^{3}$, B,Priyadharshini ${ }^{4}$ \\ ${ }^{1}$ Assistant Professor,Department of EIE,Sri Ramakrishna Engineering College,Coimbatore. \\ ${ }^{2}$ Professor,Department of EIE,Sri Ramakrishna Engineering College,Coimbatore \\ ${ }^{3}$ Assistant Professor,Department of EIE,Sri Ramakrishna Engineering College,Coimbatore \\ ${ }^{4}$ PG Student,M.E. Control and Instrumentation Engineering,Sri Ramakrishna Engineering College,Coimbatore
}

Article History:Received:11 november 2020; Accepted: 27 December 2020; Published online: 05 April 2021

Abstract:The speed control of two mass drive systems is presented in this paper. For the purpose of analysis, PI, Linear Matrix Inequality controller and Internal Model Controller are chosen. Tuning of PI controller is achieved by Zeigler Nichols method, whereas the LMI and IMC are adapted with the conventional method of tuning. The various simulations are carried out in order to analyze the performance index of these controllers and to fix the best controller, and the results are compared.

Keywords: Proportional Integral (PI), Linear Matrix Inequality (LMI), Internal Model Controller (IMC), Two mass drive system, Ziegler Nichols.

\section{INTRODUCTION}

The idea of drive systems is used by most processing industries, such as paper mills, textile mills and elevator control mechanisms, which means that a motor has been linked via a shaft to a load. These implementations are commonly known as electro-mechanical system [1]. It is noted that the system's electrical energy will rotate the mechanical shaft parts that will drive the attached load at the end of the shaft. In the case of two mechanical coupling mass drive systems, the two individuals, motor and load, are connected, so the load will appear to rotate with the motor. But, because of its non-linear behaviour, it is basically extremely difficult to achieve this synchronization [2] - [3]. Because of the long shaft between the motor and load for its mechanical coupling, this form of nonlinearity will occur in two mass drive systems, there is sure to be a speed difference between them. The speed oscillations between the motor and the load result in a decrease in the efficiency of the output and in the stability of the system. And because of the coupling shaft stresses, it also negatively influences the coupling. For nonlinear systems, stability needs to be precisely described, [4]. Therefore, special control techniques have to be investigated and improved to obtain the stable system and to improve performance.

The use of the Linear Matrix Inequality Controller is part of the implementation process. LMI's controller architecture is based on mathematical derivation. This requires the conversion process of the transfer function to variables of the state space. Then the ultimate process for the controller is to find the benefit. The Algebraic Riccati Equation (ARE) could be used to measure this benefit. In the LMI controller, the PI controller is used. With the assistance of the Zeigler Nichols system, this PI controller is tuned. The mathematical derivation also describes the Internal Model Controller. The mathematical derivation involves the method of decreasing the function of higher order transfer to the function of first order transfer. This process is called as half rule method. The conversion of the domain is then done with the help of a reduced first order equation using the pulse transfer function. The s-domain transfer function is converted to $\mathrm{z}$-domain transfer function.

For the purposes of selecting the best controller for the two mass drive systems, the simulated results are then determined. This is chosen by means of index of the controllers.

The organization of the rest of the paper can be described as follows in [II] process dynamics, and [III] controller implementation, continues with [IV] simulation results and [V] conclusion of the work.

\section{Process DyNAMics}

The characteristics and functions of the plant actually depends on the process's dynamics. A proper analysis of plant dynamics can lead to the rise of a better model for the process in concern [2] - [3]. The schematic representation of two mass systems has been given in Fig. 1. The load (M2) that also has the same M1 specification

Corresponding Author: D.Devasena, ${ }^{1}$

Assistant Professor,Department of EIE,Sri Ramakrishna Engineering College,Coimbatore. 
is driven by Motor 1 (M1). The parameters of the process involved in two mass drive systems are given as notation and described below.
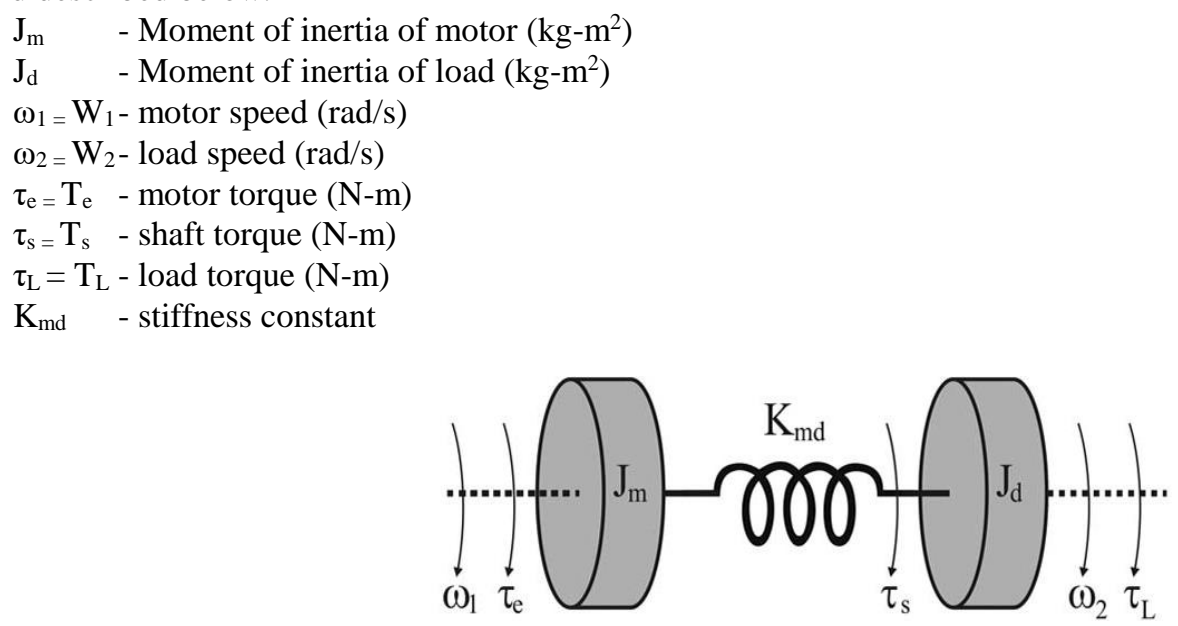

Fig. 1. Schematic diagram of Two-Mass System

Moment of inertia of motor and load, shaft stiffness were considered as constant values. It is identified that there are three state variables [2] are involved in plant dynamics namely speed of Motor $\omega 1$ and load $\omega 2$, Shaft Torque $\tau$. Based on state variable the state equations have been formulated and it is given below.

$$
\begin{aligned}
\frac{d \omega_{1}}{d t} & =\frac{1}{T_{1}} \tau_{e}-\frac{1}{T_{1}} \tau_{s} \\
\frac{d \omega_{2}}{d t} & =\frac{1}{T_{2}} \tau_{s}-\frac{1}{T_{2}} \tau_{e} \\
\frac{d \tau_{s}}{d t} & =\frac{1}{\tau_{e}} \omega_{1}-\frac{1}{\tau_{e}} \omega_{2}
\end{aligned}
$$

From above equations it is clearly mentioned that the state of the system depends on motor speed, load speed, motor torque, shaft (torsional) torque, disturbance torque, mechanical time constant of the motor, mechanical time constant of the load and the stiffness time constant [1], [2] - [3].

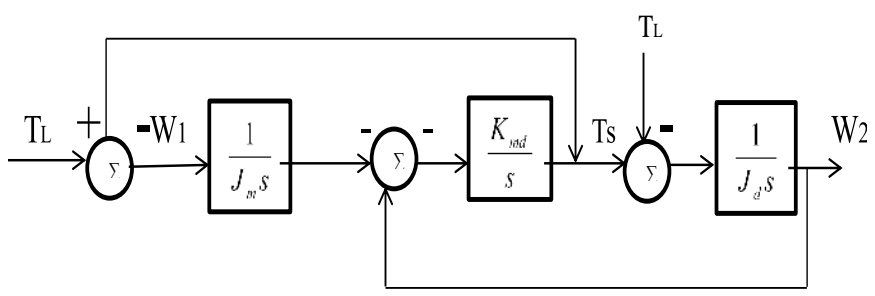

Fig. 2. Block diagram representation of two mass system with its dynamics

Fig. 2 reflects, with its dynamics, the block diagram representation of two mass systems. As the control input to the system, the electromagnetic torque of the motor is used and the angular velocity of the motor is taken from the system as the output[2]. The electromagnetic torque of the motor drives the shaft-linked load. Generally, this mixture is known as the electromechanical system[3].

As damping losses are typically considered to be relatively low, they are ignored without affecting the simulation analysis significantly[12]. Furthermore, in the simulation analysis, nonlinear parts of the actual drive system, such as backlash, mechanical hysteresis and nonlinear friction, were not taken into account. 
For further simulations, the arrival state model is known as a plant model. Implementation and review of the controller was performed on the related plant model.

\section{CONTROLLER IMPLEMENTATION}

In process sector applications, the controllers play the main role. In the device, the controllers will make the process run in the anticipated area. The deviation occurs in the process due to external and internal disturbances of intent and non-intention, causing the system to have different problems and sometimes making the environment treacherous. Different controllers are introduced to the given electromechanical system[12]-[13] to avoid this uncertainty and make the system operate in stable conditions.

Not only does the implementation of the controller end with the selection of the correct controller, but it is based on the tuning method for the chosen controller. In this work, PI, LMI and IMC controllers were introduced by adapting Ziegler Nichols and traditional tuning methods to two mass drive systems.

A generic control structure that obeys the loop feedback control mechanism is a proportional integral controller[12] and is often followed in industrial control systems. The structure of PI control is given in the equation below (4)

$$
u(t)=M V(t)=K_{p} e(t)+K_{i} \int_{o}^{t} e(t) d T
$$

"As the difference between a measured process variable and a target fixed point, a PI controller calculates a "error" value. By changing the process control inputs, the controller attempts to mitigate the error. The Ziegler Nichols tuning method has set optimized controller gain values such as $\mathrm{Kp}$ and $\mathrm{Ki}$

Clearly, in process industry applications, the PI controller offers better control efficiency and is used as a common benchmark controller to analyze various control systems. LMI and IMC controllers have been introduced and results will be compared with benchmark controllers in order to achieve maximum control efficiency greater than the PID.

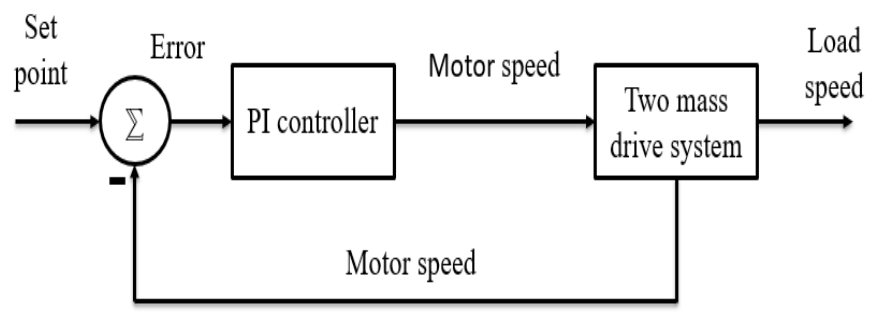

Fig. 3. Block Diagram of Two-Mass Drive System using PI controller

The Linear Matrix Inequality Controller has been introduced and the benchmark controller will be compared with the results. LMI has less peak overshoot as an advanced controller and hence becomes a benefit for the controller.

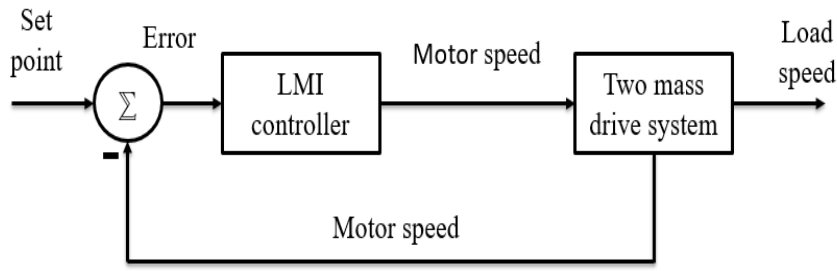

Fig. 4. Block diagram of Two-Mass Drive System using Linear Matrix Inequality controller

The improvement of the proposed controller, namely the LMI controller, is given with the help of feedback gain in the generalization and accompanied by the tuning of the PI controller[5]. The gain in feedback is calculated by the aid of the Algebraic Riccati Equation (ARE) and the gain measurement. The ARE is conferred by

$$
\mathrm{A}^{\mathrm{T}} \mathrm{P}+\mathrm{PA}-\mathrm{PAR}^{-1} \mathrm{~B}^{\mathrm{T}} \mathrm{P}+\mathrm{Q}=0
$$


The required matrix could be found in the implementation of this Algebraic Riccati Equation and after this the gain is determined by the following,

$$
\mathrm{K}=\mathrm{R}^{-1} * \mathrm{~B}^{\mathrm{T}} * \mathrm{P}
$$

Then the formula calculates the gain and then the PI controller is tuned with the help of the Ziegler Nichols method and the response is obtained for the LMI controller.

The Internal Model Controller is designed with the help of the principle of the internal model, which states that control can only be achieved if the control system en-capsulate some representation of the process to be controlled, either implicitly or explicitly. The design process begins with the process of deriving the pulse transfer function of the two mass drive systems for the transfer function. The pulse transfer function is then factorized into two distinct parts, i.e., invertible and non-invertible parts. With the help of the first order filter tuning parameter, this is followed by deriving the $\operatorname{Gimc}(\mathrm{z})$. The simulation is then completed and the reaction is collected.

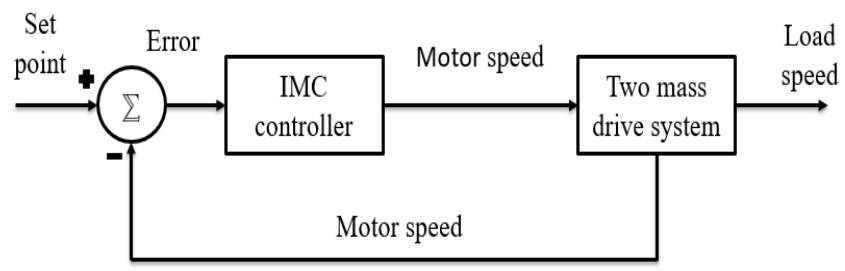

Fig. 5. Block diagram of Two-Mass Drive System using Internal Model controller

\section{Simulation Results}

Conventional PI controllers, Linear Matrix Inequality controllers and Internal Model Controllers have studied the performance of the model system. The output index of these controllers is determined and the values are compared to the LMI controller's characteristics.

The PI controller is tuned to give the best output here. The optimized values of $\mathrm{Kp}$, Ki gain were determined using the tuning technique of the closed loop Ziegler-Nichols. The efficiency of two PI controller mass drive systems is shown in Fig. 6. It is important to remember that the synchronization between the engine and the load is perfectly accomplished using the PI controller.

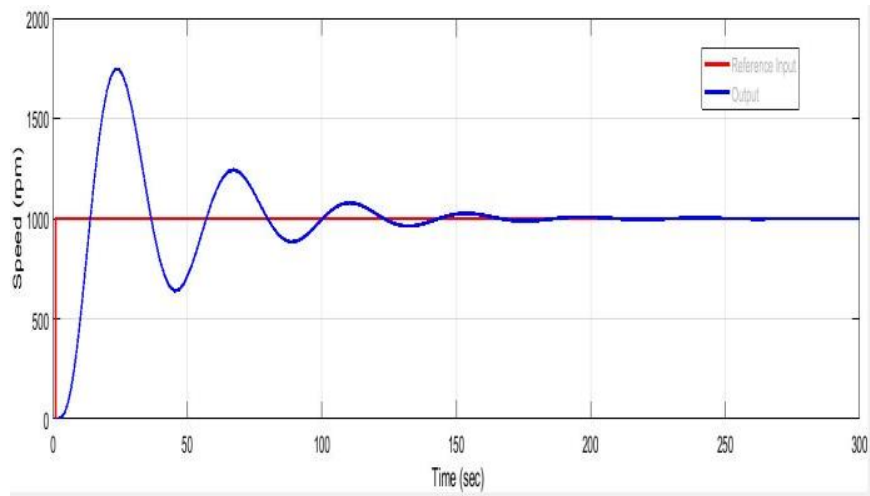

Fig. 6. Response of two mass drive system with PI controller

The conventional tuning method of the LMI controller has been tuned and the result is shown in Fig. 7. From the answer, it is clear that in the case of two mass drive systems, the maximum peak overshoot is less, which is the key index to be discussed. 


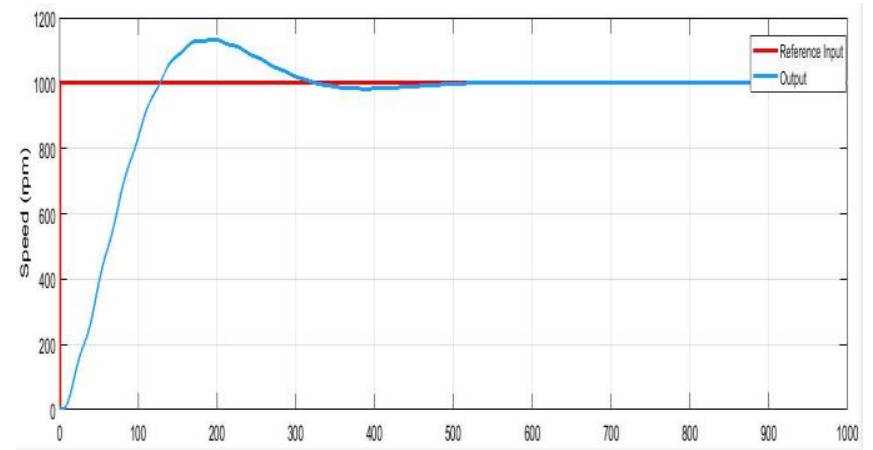

Fig. 7. Response of two mass drive system with LMI controller

Using the conventional tuning method, the IMC controller was tuned and the result is shown in Fig. 8. It is clear from the reply that the controller is better than the LMI controller and the PI controller. Therefore, the IMC's response using the two mass drive systems shows no overshoot.

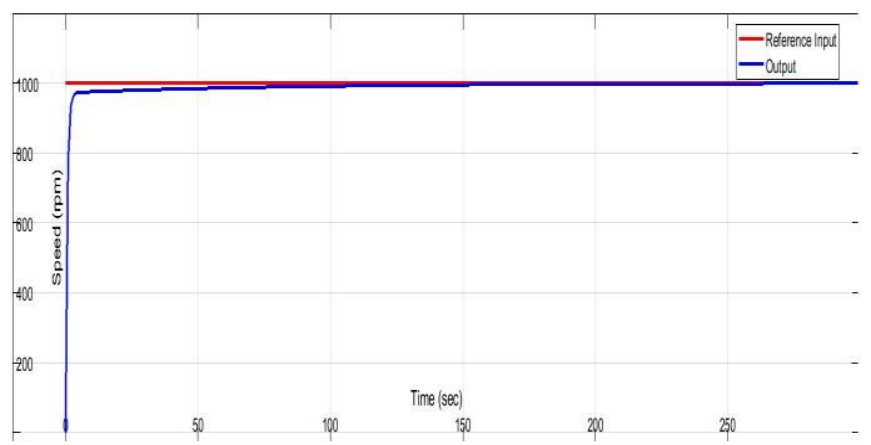

Fig. 8. Response of two mass drive system with IMC controller

The performance index is mandatory for analysis of the performance of the controller. The following output indices, namely Settling Time, Rise Time, Peak Time and Peak Overshoot, are evaluated here to define the nominal conditions of the controller.

TABLE I

COMPARISON OF PERFORMANCE INDEX VALUES

\begin{tabular}{|l|c|c|c|}
\hline Parameters & PI & LMI & IMC \\
\hline Settling time (sec) & 250 & 440 & 70 \\
\hline Rise time (sec) & 13.5 & 140 & - \\
\hline Peak time (sec) & 30 & 200 & - \\
\hline Peak overshoot (\%) & 82.3 & 10 & No \\
\hline
\end{tabular}

Table 1 shows that the values for the different performance indices are $1000 \mathrm{rpm}$ for the PI, IMC and LMI controllers when the set point reference is set. By identifying the appropriate controller for the process, the goal of this work converges to one point. This can be achieved by comparing the IMC and the controller with the standard PI and LMI controller benchmarks. IMC is satisfied with the results. In this respect, the LMI has only 10 percent peak overshoot and IMC has no peak overshoot. The peak overshoot is certainly the main index to be addressed in the two mass drive system. IMC is better than the other controllers with reference to the other parameter specifications. The Internal Model Controller is therefore the most appropriate one for the two mass drive systems.

\section{V.CONCLUSION}

This paper focused on the implementation of controllers for two mass drive systems. The plant model was obtained and a number of simulations were performed using PI, LMI and IMC controllers on that model. For PI, 
LMI and IMC, Zeigler Nichols tuning and conventional tuning methods were respectively implemented. In order to identify and fix better controllers for two mass drive systems, the objective then converges. Compared to PI and IMC controllers, the controller performance indices and the performance index of the LMI controller were then calculated. It is concluded that LMI is a deserving controller that provides two mass drive systems with satisfied performance in both transient and steady state behavior. In the manufacturing and real-time implementation of two mass drive systems, this modeling study and its simulation results may be used. In the two mass drive systems, the study can be extended to design controllers with various disturbances such as shocks, vibrations, torsion, etc.

\section{ACKNOWLEDGMENT}

This project was funded and carried out at Department of Electronics and Instrumentation Engineering, by the Sri Ramakrishna Engineering College, Coimbatore. We would like to thank our Management, Principal, faculty members and students for supporting us with the infrastructure to carry out the project work.

\section{REFERENCES}

G. Shahgholian, "Modeling and Simulation of a Two-Mass Resonant System with Speed Controller", International Journal of Information and Electronics Engineering, Vol. 3, No. 5, pp. 448-452, 2013.

K. Erenturk, "Fractional-Order $\mathrm{PI}^{\lambda} \mathrm{D}^{\mu}$ and Active Disturbance Rejection Control of Nonlinear Two-Mass Drive System", IEEE Trans. on Industrial Electronics, Vol. 60, No. 9, pp. 3806-3813, 2013.

S. Juraitis, R. Rinkeviciene, and A. Kilikevicius, "Experimental Investigation of Two-mass Electromechanical System”, Elektronika IR Elektrotechnika, Vol. 18, No.10, 2012.

A. Qadir, and B.A.Aminudin., "Comparative Study on Control Method for Two-Mass Systems", International Journal on Advanced Science Engineering Information Technology, Vol. 2, No. 3, pp. 63-68, 2012.

P. Apkarian, and H.D.Tuan, “Parametrized LMIs in control theory”, SIAM J. Contr. Optimizat., Vol.38, pp. 12411264, 2000.

T. Aleksei, P. Eduard, and B. Juri, “A Flexible MATLAB Tool for Optimal Fractional-order PID Controller Design Subject to Specifications", Proceedings for Chines Conference, China July 25-27, pp. 4698-4703, 2012.

S.Cius, and E.R.Cien, "Simulation of Transients in the Mechanical Part of Electromechanical System", Proceedings of the 10th International Conference on Mathematical Modelling and Analysis, Trakai, pp. 155-162, 2005.

Stephanopoulos, "Chemical Process Control”, Prentice Hall of India, ( ${ }^{\text {th }}$ Ed.), 2008.

P. Gahinet, and P.Apkarian, "A Linear matrix inequality approach to $\mathrm{H}_{\infty}$ Control”, International Journal of Nonlinear Robust Controller, Vol.4, pp. 421-448, 1994.

C. K. Mishra, S. Jebakumar, and Mishra, "Controller Selection and Sensitivity Check on the Basis of Performance Index Calculation", International Journal of Electrical, Electronics and Data Communication, Vol. 2, No. 1, pp. 91-93, 2014.

B.G. Liptak, "Instrument Engineers Handbook, Volume Two: Process control and optimization", CRC press, $\left(4^{\text {th }}\right.$ Ed.), 2012.

Y. Dharshan, K. Srinivasan, and B. Sharmila, "Optimization Technique for Networked Control DC Motor with Network-Induced Delays and Noises”, IEEE Xplore International Conf. ICTUS, 18-20 Dec, Dubai, pp. 756762. 2017.

M. Pradeep, B. Sharmila, D. Devasena, and K. Srinivasan, "PID and $\mathrm{PI}^{\lambda} \mathrm{D}^{\mu}$ Controller Implementation for Speed Control Analysis of Two Mass Drive System", IEEE International Conf. on Communication and Signal Processing, 3-5 April, India, pp. 731-734. 2018

C. Jing, Y.Jiayu and C. Zhongyi, "IP controller Design for Uncertain Two-Mass Torsional System Using TimeFrequency Analysis", Shock and Vibration, Vol. 2018, pp.1-9, 2018

Srinivasan K., (2015), "Design of model preictive controller and a fuzzy controller for a pH control process", International Conference on Electrical, Instrumentation and Communication Engineering, pp. 99-104.

Sharmila B, Swapna P, (2016), "Monitoring, control and performance analysis of aprocess through wireless network", IEEE conferenceproceedings, Vol. 1, pp. 1-6.

Y.Dharshan, K.Srinivasan and B.Sharmila,(2019), "Implementation of Model Predictice Controller for Neutralization of pH Process", International Journal of Advanced Research in Dynamical and Control System, Vol.11.

M.Nagarajapandian and B.Sharmila, (2019), "Reconfigurable Controller Design forbased controllers used in multivariable methods", International Journal of Advanced Research in Dynamical and Control System, Vol.11 